\title{
Failure to prevent medication errors: We need smarter nearly error proof systems
}

\author{
Loren G. Yamamoto $^{1,2^{*}}$, Kyle M. Watanabe ${ }^{1}$, Joan E. Kanemori ${ }^{2}$ \\ ${ }^{1}$ Department of Pediatrics, University of Hawai’i John A. Burns School of Medicine, Honolulu, USA \\ ${ }^{2}$ Kapi’olani Medical Center for Women \& Children, Honolulu, USA \\ Email: Loreny@hawaii.edu
}

Received 4 January 2013; revised 5 February 2013; accepted 13 February 2013

Copyright (C) 2013 Loren G. Yamamoto et al. This is an open access article distributed under the Creative Commons Attribution License, which permits unrestricted use, distribution, and reproduction in any medium, provided the original work is properly cited.

\begin{abstract}
Purpose: To determine if nurses are able to identify medication errors that have the potential to bypass computer physician order entry (CPOE) and smart ordering systems. Background: Medical care systems employ computer "smart" systems to reduce medication errors by using artificial intelligence (preprogrammed methods of decision support and error reduction). However, these systems are not perfect and they can be bypassed. Nurses who carry out the order represent the last check point in error prevention prior to the administration of medication orders. Methods: A paper exercise was created with 513 physician orders. Nurses were asked to indicate whether they would carry out the order, refuse to carry out the order, consult a pharmacist for clarification, or carry out the order with special precautions. Nurses were given the option of using any nursing or medical reference. Results: The rate of correctly identifying 23 of the contraindicated orders was low. Both experienced and inexperienced nurses had high rates of not identifying the errors despite similar use of references and requests for assistance from pharmacists. Conclusions: This study demonstrates that if an error escapes a smart system, nurses were able to identify most of these errors, but not all of these. The current system features high stress, self-esteem issues, time pressure, high volume, and high risk. The system must change radically to meet the public's expectations of being nearly error free which can only be achieved with smarter systems that are more resistant to human errors.
\end{abstract}

Keywords: Medication Errors; Patient Safety; Error Reduction; Smart Systems

\footnotetext{
"Corresponding author.
}

\section{INTRODUCTION}

Medical care systems employ computer "smart" systems to reduce medication errors by using preprogrammed methods of decision support and error reduction. Computer physician order entry (CPOE) is one strategy that electronic medical records (EMR) and care systems commonly employ to reduce errors. Computer checks programmed into these systems have the potential to prevent many errors [1,2]. Many hospitals use these systems coupled with automated medication dispensing units and other error reduction systems [3]. However, computer based systems are not infallible [4,5]. Nurses who carry out the order represent the last check point in error prevention prior to the administration of medication orders. The five rights of medication administration (right patient, drug, dose, route, time) do not prevent all medication errors [6,7]. The nine rights of medication administration add the right documentation, action, form, and response [8]. The purpose of this study is to determine if nurses are able to identify medication errors that have the potential to avoid detection by CPOE and smart ordering systems. Understanding the factors and circumstances that contribute to errors is important to guide the efforts of future error reduction strategies to help determine if the greatest error reduction yield can be achieved by further modifying human factors or modifying delivery components and machinery to create a future system that is nearly error free.

\section{METHODS}

Nurses at a children's hospital pediatric service using a paperless electronic medical record with computer physician order entry (CPOE) since 2008 were asked to participate in this IRB approved study. Prior to 2008 a different EMR was utilized by most of the hospital, but this system was not employed in the emergency department. 
A one page table was created as a paper exercise. The form is shown in Figure 1. The table was constructed to present occasional situations in which drug allergies and medical conditions would contraindicate or create a cautionary situation for the administration of some of the medication or procedure orders. Each of the 19 columns represents a physician order. Study subjects were informed that each cell in the table represents a different patient with no other concurrent medications, allergies, or underlying medical conditions other than that assigned to the cell by the row and column, which greatly simplified the exercise. This figure resulted in 513 cells all of which required a response. This method was selected so that the entire study exercise could be completed on a single sheet of paper. A multi-paged document with 513 question items would have the appearance of being a greater burden in addition to having a more complex and intimidating initial appearance. The study was designed to have a large number of distracters (minor medication orders with no contraindications) and the need to complete 513 items made the exercise difficult and long to simulate what nurses actually do in that most of the orders they receive are correct and safe, but there is an oc- casional error that occurs. Fatigue is a factor that was built into this exercise.

For each cell of the table, study subjects were asked to enter a mark indicating one of four possibilities: 1) I will carry out the order (the nurse will carry out the order without further clarification); 2) I will not carry out the order (the nurse will not carry out the order with the current information; a "refusal"); 3) I am not sure about this order, so I will ask a pharmacist (a discussion with a pharmacist is necessary to clarify whether the order can be carried out as presented); or 4) Carrying out this order requires special precautions. The special precautions examples that were given were vancomycin must be given slowly following a pre-medication with diphenhydramine, and a blood transfusion that requires special cross matching, identification, specification of irradiation, and filters. Vancomycin and blood transfusion orders were not part of the study exercise.

The items included in the study document (Figure 1) were based on errors that had occurred in the past or that have been published in the literature. However, most of the cells on the form were routine orders without problems that were commonly carried out in the pediatric

\begin{tabular}{|c|c|c|c|c|c|c|c|c|c|c|c|c|c|c|c|c|c|c|c|c|c|}
\hline & $\begin{array}{l}\text { Doctor's written order: } \\
\text { Will you carry it out? } \\
\mathrm{OK}=\text { I will do it } \\
\mathbf{X}=\text { I will not do it } \\
?=\text { Not sure, I will ask } \\
\text { pharmacist } \\
\text { Sp = Special precaution }\end{array}$ & 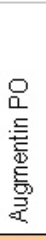 & 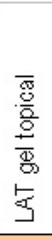 & 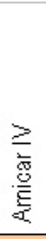 & 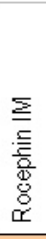 & 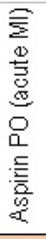 &  & $\begin{array}{l}\circ \\
\stackrel{0}{1} \\
\frac{5}{8} \\
\stackrel{0}{9} \\
\end{array}$ & 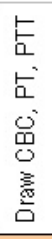 & 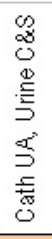 & $\begin{array}{l}\geq \\
\frac{\overline{0}}{\circ} \\
\frac{8}{\circ} \\
\frac{0}{2}\end{array}$ & 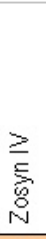 & 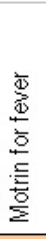 & 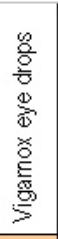 & 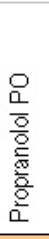 & 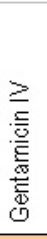 & 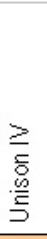 & 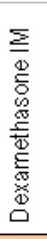 & 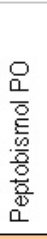 & 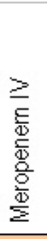 & 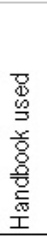 \\
\hline \multirow{8}{*}{$\frac{\infty}{\frac{1}{0}}$} & Amoxicillin & $x$ & & & & & & & & & & $x$ & & & & & $x$ & & & & \\
\hline & Ceclor & & & & $x$ & & & & & & & & & & & & & & & & \\
\hline & Bactrim & & & & & & & & & & & & & & & & & & & & \\
\hline & Clindamycin & & & & & & & & & & & & & & & & & & & & \\
\hline & Omnicef & & & & $x$ & & & & & & & & & & & & & & & & \\
\hline & Cipro & & & & & & & & & & & & & $x$ & & & & & & & \\
\hline & Amakacin & & & & & & & & & & & & & & & $x$ & & & & & \\
\hline & Lidocaine & & $x$ & & & & & & & & & & & & & & & & & & \\
\hline \multirow{10}{*}{$\begin{array}{l}\infty \\
\frac{\Phi}{\sigma} \\
\frac{0}{\overline{0}}\end{array}$} & Tylenol & & & & & & & $x$ & & & & & & & & & & & & & \\
\hline & Motrin & & & & & $x$ & & & & & & & $x$ & & & & & & $x$ & & \\
\hline & \begin{tabular}{|l} 
Latex \\
\end{tabular} & & & & & & & & $S p$ & $S p$ & & & & & & & & & & & \\
\hline & Neosporin & & & & & & & & & & & & & & & $x$ & & & & & \\
\hline & Shrimp & & & & & & & & & & & & & & & & & & & & \\
\hline & Eggs & & & & & & & & & & $x$ & & & & & & & & & & \\
\hline & MSG & & & & & & & & & & & & & & & & & & & & \\
\hline & Soy & & & & & & & & & & $x$ & & & & & & & & & & \\
\hline & Grass & & & & & & & & & & & & & & & & & & & & \\
\hline & Cat fur & & & & & & & & & & & & & & & & & & & & \\
\hline \multirow{10}{*}{ 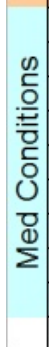 } & \begin{tabular}{|l|} 
Leukemia \\
\end{tabular} & & & & & $x$ & & & & & & & $x$ & & & & & $x$ & $x$ & & \\
\hline & HIV & & & & & & & & & & & & & & & & & & & & \\
\hline & Hypertension & & & & & & & & & & & & & & & & & & & & \\
\hline & Home peritoneal dialysis & & & & & & & & & & & & & & & & & & & & \\
\hline & Asthma & & & & & & & & & & & & & & $x$ & & & & & & \\
\hline & Rotavirus diarrhea & & & & & & & & & & & & & & & & & & & & \\
\hline & Meningomyelocele & & & & & & & & $S p$ & $S p$ & & & & & & & & & & & \\
\hline & Hemophilia & & & & & $x$ & & & & & & & $x$ & & & & & & $x$ & & \\
\hline & Influenza A & & & & & & & & & & & & & & & & & & & & \\
\hline & Handbook used & & & & & & & & & & & & & & & & & & & & \\
\hline
\end{tabular}

Figure 1. Data form. 
units. Error items and special precaution items are summarized in Table 1. Spelling errors were not considered to be practice errors for the purpose of this study.

Nurses were approached while on duty, in person by one of the study investigators; however, they could complete the study form at their leisure when not on duty. Nurses were asked to self-describe their number of years of nursing experience and identify themselves as work- ing primarily in the emergency department (ED), pediatric intensive care unit (PICU), pediatric ward unit, or transport team. This was done to determine if the number of errors or strategies to reduce errors were different amongst the different nursing specialties and experience levels. Errors were defined as listed in Table 1.

In order to simulate actual patient care, subjects were instructed to complete the table as if they were working

Table 1. Study Definition of Errors for drug allergies and medical conditions. Misspellings and abbreviations are in quotes.

\begin{tabular}{|c|c|c|}
\hline Drug allergy/condition & Error & Reason for inclusion \\
\hline Amoxicillin & Augmentin PO & $\begin{array}{l}\text { Common allergy and commonly used drug. Some patients claim to be allergic to amoxicillin } \\
\text { but they can take Augmentin indicating that Augmentin is not uncommonly given to amoxicillin } \\
\text { allergic patients. }\end{array}$ \\
\hline Amoxicillin & Zosyn IV & Common allergy. Combination drug that might not be easily appreciated to be a penicillin. \\
\hline Amoxillin & “Unison” IV & $\begin{array}{l}\text { Common allergy. Combination drug that might not be easily appreciated to be a penicillin. } \\
\text { Unasyn is sometimes misspelled as "Unison". }\end{array}$ \\
\hline Ceclor & Rocephin IM & Common allergy. Commonly used drug. \\
\hline Omnicef & Rocephin IM & Less common allergy but still cephalosporin class. Commonly used drug. \\
\hline “Cipro” & Vigamox eye drops & $\begin{array}{l}\text { Ciprofoxacin frequently abbreviated as "Cipro". Vigamox sounds like a penicillin, but it is } \\
\text { actually a quinolone. }\end{array}$ \\
\hline “Amakacin” & Genamicin IV & $\begin{array}{l}\text { Amikacin is commonly misspelled. It has been implicated in serious sound alike order errors with } \\
\text { Amicar (epsilon amino caproic acid). }\end{array}$ \\
\hline Lidocaine & LAT gel topical & $\begin{array}{l}\text { Lidocaine and tetracaine are components of LAT gel which is a common standing order item in } \\
\text { EDs that can bypass CPOE safeguards. }\end{array}$ \\
\hline Tylenol & Vicodin PO & $\begin{array}{l}\text { Commonly used combination medication. Its main component is a narcotic analgesic but it also } \\
\text { contains acetaminophen. }\end{array}$ \\
\hline Motrin & Aspirin PO & Cross allergy. Commonly used drugs. \\
\hline Motrin & Motrin for fever & $\begin{array}{l}\text { Commonly used drugs. It should be clear that a patient with a Motrin allergy should not be given } \\
\text { Motrin, yet we suspect that this will occur when clinicians are overwhelmed with work. }\end{array}$ \\
\hline Motrin & Pepto-Bismol PO & $\begin{array}{l}\text { Pepto-Bismol contains bismutb subsalicylate which has cross reactivity with aspirin and } \\
\text { non-steroidal anti-inflammatory drugs (NSAID) allergy. }\end{array}$ \\
\hline Neosporin & Gentamicin IV & Neosporin is over the counter, commonly used, and contains neomycin (an aminoglycoside). \\
\hline Eggs, soy & Propofol & $\begin{array}{l}\text { Propofol contains egg proteins and soybean oil. Further questioning is required and it is } \\
\text { commonly contraindicated. }\end{array}$ \\
\hline Latex & $\begin{array}{l}\text { Draw CBC, PT, PTT, } \\
\text { Cath UA, Urine C\&S }\end{array}$ & $\begin{array}{l}\text { (precaution, not error) Special precautions to utilize a non-latex tourniquet and a non-latex } \\
\text { urinary catheter. }\end{array}$ \\
\hline Leukemia & Aspirin, Motrin & Anti-platelet effect is detrimental to patients with low platelet conditions. \\
\hline Leukemia & Dexamethasone & $\begin{array}{l}\text { Corticosteroids are part of leukemia treatment and should best be given by oncologists under their } \\
\text { direction. }\end{array}$ \\
\hline Leukemia & Pepto-Bismol PO & Anti-platelet effect of bismuth subsalicylate is detrimental to patients with low platelet conditions. \\
\hline Asthma & Propranolol & $\begin{array}{l}\text { Beta blockers are harmful in asthmatics since they precipitate bronchospasm and block the } \\
\text { effectiveness of beta agonists. }\end{array}$ \\
\hline Hemophilia & Aspirin, Motrin & Anti-platelet effect is detrimental to patients with hypocoagulation conditions. \\
\hline Hemophilia & Pepto-Bismol PO & $\begin{array}{l}\text { Anti-platelet effect of bismuth subsalicylate is detrimental to patients with hypocoagulation } \\
\text { conditions. }\end{array}$ \\
\hline Meningo-Myelocele & $\begin{array}{l}\text { Draw CBC, PT, PTT, } \\
\text { Cath UA, Urine C\&S }\end{array}$ & $\begin{array}{l}\text { These patients should be assumed to be allergic to latex (precaution, not error). Special precautions } \\
\text { to utilize a non-latex tourniquet and a non-latex urinary catheter. }\end{array}$ \\
\hline
\end{tabular}


therefore, participants could use references without restriction to look up any items on the form. Use of a reference was marked on the data form. Subjects were asked to refrain from discussing the study cases with other nurses since this would reduce the number of potential study subjects. Data collection took place from July 2009 to March 2010. Data from these forms were entered by one investigator, then entered by a second investigator independently. The two data entry sets were compared by a computer algorithm. Data entries that differed were reconciled by reviewing the original data forms to yield a single data set.

\section{RESULTS}

A convenience sample of 34 nurses completed the survey. Amongst the study subjects, the average years of nursing experience was 7 (range 1 to 33). Seven nurses did not indicate their number of years of experience. Nurse participants came from the following units: ED 18, PICU 6, ward 2, transport 1 , and 7 did not identify their unit. ED nurses work in a unit that has a pediatric volume of $67 \%$ of all the patients. The other $33 \%$ are adults, of which, many are obstetrics/gynecology conditions since the hospital is a women's and children's hospital. Ward and PICU nurses only manage pediatric patients. Other nurses could float between pediatric and adult units in the hospital.

The data form included 23 cells that prior to the study were determined to be marked as "I will not do it" and four cells should have required special precautions (i.e., these were the "correct" answers in the scoring key).

Table 2 summarizes the percentage of the nurses who recognized each of the 15 drug allergy contraindicated medication errors. Many of the errors were not identified.

Table 2 also summarizes the percentage of the nurses who recognized each of the eight medical condition contraindicating medication errors. While these were relative contraindications, antiplatelet drugs (aspirin, ibuprofen, bismuth subsalicylate) should not be given routinely to patients with a compromised bone marrow or a coagulopathy. Special precautions or confirming the appropriateness of these medications should be confirmed with a hematologist. Similarly, corticosteroids should not be given to patients with leukemia without first discussing this with a hematologist/oncologist.

Table 3 summarizes the use of special precautions. The special precautions included in the study exercise were the use of non-latex gloves, tourniquets, and catheters to patients with a known latex allergy and patients with a meningomyelocele.

Of the 34 nurses, 3 identified less than $25 \%$ of the 27 error and special precaution items, 19 identified 25\% to
$50 \%$ of these, 9 identified $51 \%$ to $67 \%$ of these, and 3 identified $70 \%$ to $78 \%$ of these.

Table 4 summarizes the overall frequency of refusing to carry out an appropriate order, consulting a pharmacist, using unnecessary special precautions, and using a reference. Orders with frequencies $1 \%$ or less were not listed in Table 4.

There was no significant difference in the number of references used by less experienced nurses (less than 5 years) (mean of 7.5 references) compared to more experienced nurses (mean of 6.5 references). Three of the more experienced nurses used 17, 18, and 23 references respectively. The highest numbers of references used by less experienced nurses were 8,11 , and 15 . There was no significant difference in the mean number of the 23 error orders that were correctly identified by less experienced nurses (mean 12.5) compared to more experienced nurses (mean 14.0). There was no significant difference in the sum of orders refused, pharmacist assistance, and special precautions requests by less experienced nurses (mean 44) compared to more experienced nurses (mean 66).

\section{DISCUSSION}

The basic conclusion is that humans make errors. Existing care models are reliant on humans. Five to nine rights of medication administration, cultures of patient safety, CPOE, smart systems, and bar coding systems are reliant on humans who make errors. Existing care models can be tweaked and improved but are still dependent on humans. This study mimics some of the human nature factors that contribute to errors that are discussed below. Rather than accepting the conclusion that errors will inevitably occur because humans make errors, a future direction is proposed.

This study took place in a children's hospital. It should be assumed that these nurses are more experienced with pediatric conditions and medications and less experienced with adult conditions and medications. Some study limitations include the artificial nature of the paper exercise. Since study subjects were volunteers, there was some degree of motivation in the desire to help with the research, but the motivation was not the same as performing actual patient care. The completion times were not recorded. Some subjects completed the survey on the same day of the consent during their work shift, while other nurses completed the survey at home. Because the survey was long, some time pressure to complete this was present, but it likely was not the same as actual patient care, in that no patients were "waiting", no colleagues were involved, and no supervisor was overseeing their work. While our sample size is small, the results are clear. No nurse identified more than $78 \%$ of the errors 
Table 2. Summary of nurse actions for allergy or medical condition contraindicated medication orders and special pre-cautions. Trade names are used (in quotes) below if the trade name was used on the data form.

\begin{tabular}{|c|c|c|c|}
\hline Administer drug to a patient with an allergy or medical condition & Error rate & $\begin{array}{l}\text { Will not carry } \\
\text { out order }\end{array}$ & $\begin{array}{l}\text { Asked for pharmacist } \\
\text { or special precautions }\end{array}$ \\
\hline "Augmentin" (amoxicillin/clavulinate) to a patient with an amoxicillin allergy. & $3 \%$ & $91 \%$ & $6 \%$ \\
\hline "Zosyn” (piperacillin/tazobactam) to a patient with an amoxicillin allergy. & $41 \%$ & $47 \%$ & $12 \%$ \\
\hline $\begin{array}{l}\text { "Unison” (a dliberate misspelling of Unasyn) (ampicillin/sulbactam) to a patient with an } \\
\text { amoxicillin allergy. }\end{array}$ & $32 \%$ & $44 \%$ & $24 \%$ \\
\hline "Rocephin” (ceftriaxone) to a patient with a “Ceclor” (cefaclor) allergy. & $50 \%$ & $35 \%$ & $15 \%$ \\
\hline "Rocephin" (ceftriaxone) to a patient with an "Omnicef” (cefdinir) allergy. & $35 \%$ & $50 \%$ & $15 \%$ \\
\hline "Vigamox" (moxifloxacin) to a patient with an "Cipro" (ciprofloxacin) allergy. & $76 \%$ & $15 \%$ & $9 \%$ \\
\hline Gentamicin to a patient with an amikacin allergy. & $62 \%$ & $24 \%$ & $15 \%$ \\
\hline "LAT" (lidocaine, adrenaline, tetracaine) gel to a patient with a lidocaine allergy. & $21 \%$ & $74 \%$ & $6 \%$ \\
\hline $\begin{array}{l}\text { "Vicodin” (acetaminophen/ hydrocodone) to a patient with a “Tylenol” (acetaminophen) } \\
\text { allergy. }\end{array}$ & $26 \%$ & $68 \%$ & $6 \%$ \\
\hline Aspirin to a patient with an "Motrin" (ibuprofen) allergy. & $62 \%$ & $18 \%$ & $21 \%$ \\
\hline "Motrin" (ibuprofen) to a patient with a "Motrin" (ibuprofen) allergy. & $6 \%$ & $94 \%$ & 0 \\
\hline "Pepto-Bismol” (bismuth subsalicylate) to a patient with an “Motrin” (ibuprofen) allergy. & $79 \%$ & $6 \%$ & $15 \%$ \\
\hline Gentamicin to a patient with an "Neosporin" (neomycin, bacitracin, polymixin) allergy. & $91 \%$ & $6 \%$ & $3 \%$ \\
\hline Propofol to a patient with egg allergy. & $35 \%$ & $56 \%$ & $9 \%$ \\
\hline Propofol to a patient with soy allergy. & $32 \%$ & $56 \%$ & $12 \%$ \\
\hline Aspirin to a patient with leukemia. & $50 \%$ & $15 \%$ & $35 \%$ \\
\hline "Motrin" (ibuprofen) to a patient with leukemia. & $82 \%$ & $6 \%$ & $12 \%$ \\
\hline Dexamethasone to a patient with leukemia. & $65 \%$ & $9 \%$ & $26 \%$ \\
\hline "Pepto-Bismol” (bismuth subsalicylate) to a patient with leukemia. & $82 \%$ & $6 \%$ & $12 \%$ \\
\hline Propranolol to a patient with asthma. & $62 \%$ & $18 \%$ & $21 \%$ \\
\hline Aspirin to a patient with hemophilia. & $12 \%$ & $74 \%$ & $15 \%$ \\
\hline "Motrin” (ibuprofen) to a patient with hemophilia. & $38 \%$ & $41 \%$ & $21 \%$ \\
\hline "Pepto-Bismol” (bismuth subsalicylate) to a patient with hemophilia. & $71 \%$ & $26 \%$ & $3 \%$ \\
\hline
\end{tabular}

Table 3. Carrying out orders requiring special precautions.

\begin{tabular}{lcc}
\hline \multicolumn{1}{c}{ Order } & $\begin{array}{c}\text { Refusal, pharmacist, or special } \\
\text { precautions requested }\end{array}$ & $\begin{array}{c}\text { Special precautions } \\
\text { not requested }\end{array}$ \\
\hline Phlebotomy on a patient with latex allergy & $15 \%$ & $85 \%$ \\
Straight urinary catheterization on a patient with latex allergy & $35 \%$ & $65 \%$ \\
Phlebotomy on a patient with a meningomyelocele. & $3 \%$ & $97 \%$ \\
Straight urinary catheterization on a patient with meningomyelocele & $3 \%$ & $97 \%$ \\
Medications orders for a patient on home peritoneal dialysis (four examples listed below) & & $41 \%$ \\
"Amicar" (epsilon amino caproic acid) & $59 \%$ & $74 \%$ \\
Propofol & $26 \%$ & $50 \%$ \\
Gentamicin & $50 \%$ & $53 \%$ \\
Meropenem & $47 \%$ & \\
\hline
\end{tabular}


Table 4. For appropriate orders, frequency of refusing to carry out order, consulting a pharmacist, using unnecessary special precautions.

\begin{tabular}{|c|c|c|c|}
\hline & Will not carry out order & $\begin{array}{l}\text { Asked for pharmacist } \\
\text { or special precautions }\end{array}$ & Used reference \\
\hline “Augmentin” (amoxicillin/clavulinate) & $4 \%$ & $4 \%$ & $29 \%$ \\
\hline "LAT gel topical” (lidocaine, adrenaline, tetracaine) & $1 \%$ & $7 \%$ & $18 \%$ \\
\hline “Amicar” (epsilon amino carpoic acid) & $4 \%$ & $6 \%$ & $71 \%$ \\
\hline “Rocephin” (ceftriaxone) & $3 \%$ & $7 \%$ & $32 \%$ \\
\hline Aspirin & $1 \%$ & $5 \%$ & $24 \%$ \\
\hline Propofol & $3 \%$ & $3 \%$ & $26 \%$ \\
\hline “Zosyn” (piperacillin/tazobactam) & $4 \%$ & $5 \%$ & $35 \%$ \\
\hline "Vigamox" (moxifloxacin) & $1 \%$ & $2 \%$ & $26 \%$ \\
\hline Propranolol & $2 \%$ & $3 \%$ & $29 \%$ \\
\hline Gentamicin & $3 \%$ & $4 \%$ & $26 \%$ \\
\hline “Unison” (a deliberate misspelling of Unasyn-ampicillin/sulbactam) & $4 \%$ & $19 \%$ & $35 \%$ \\
\hline Dexamethasone & $2 \%$ & $5 \%$ & $15 \%$ \\
\hline “Pepto-Bismol” (bismuth subsalicylate) & $1 \%$ & $3 \%$ & $24 \%$ \\
\hline Meropenem & $4 \%$ & $4 \%$ & $44 \%$ \\
\hline
\end{tabular}

and only 13 of 34 nurses were able to identify more than half of the errors. This is important because current error reduction systems have the potential to reduce errors, but not eliminate them [1,9]. Assuming that the smart system prevents errors, could lead to excessive reliance on the error reduction features, leading to complacency which maintains the potential for error.

Smart systems utilizing hardwiring strategies can be easily bypassed with verbal orders, written orders, standing orders, free text orders, and pharmacist initiated orders. Computers usually require exact spellings and are intolerant of simple errors such as misspelling words or undefined terms [10]. Unasyn was misspelled as "Unison" in this study. Amikacin was misspelled as "amakacin" in this study. Gentamicin is frequently misspelled as gentamycin. Propranolol is frequently misspelled as "propanolol”. Precision and correct spelling are advantageous since sound alike and spelled alike drug names such as cisplatin/carboplatin, amikacin/ Amicar, and propranolol/propofol can result in drug selection errors by humans that are more tolerant of spelling errors. Note that one expert resource did not identify amikacin/Amicar as a sound alike [11], yet another resource confirmed that these two drugs have been mistaken for each other [12]. Related medications (e.g., bismuth subsaliclylate, ibuprofen, and aspirin) with cross allergies are difficult to fully program. Some allergies are inappropriately linked with each other (e.g., seafood, iodine, iodinated contrast, non-ionic contrast). Humans are susceptible to nomenclature tricks (e.g., "Vigamox" is a quinalone and not a penicillin).

Nurses carry out a large number of orders per shift. Questioning each order slows down patient care and patient flow. Their nursing self-esteem is compromised if they challenge an order and the order turns out to be correct. Questioning and challenging the correctness of an order to improve patient safety is encouraged, yet there are inherent human nature forces (workload, task completion demands, and self-esteem) that work against this to discourage this practice even if this compromises patient safety [9]. Additionally, nurses are not primarily responsible for medication selection and dosing, yet they are expected to prevent errors in this realm.

In the clinical practice in our ED, nurses are told that they must understand the clinical reason for each order that is presented to them. They cannot carry out an order without understanding the justification for it. They are required to ask for two reasons: 1 ) It might be an error, in which case it needs to be stopped; 2) It is a gap in their clinical knowledge and it is the perfect time to learn this.

This study confirms some of these human nature factors. The study participants could have looked up all the drugs in a reference, consulted a pharmacist for all the orders, or utilized "special precautions" for all the orders. However, the study was deliberately made long and contained many appropriate orders that are often routine. This simulates a long shift with numerous tasks. Although there was no time limit for the study, they most 
certainly wanted to complete the exercise and go on to other things in their daily lives. Nurses must identify the few high risk orders from the large number of low risk orders. This study demonstrates that this task is too difficult, making this an unrealistic expectation. Having a pharmacist or a second clinician of any type is likely to reduce the errors further, but this is expensive, it slows the system down, and it still utilizes a human.

It might seem inexplicable and inexcusable for two (6\%) of the study participants to have given "Motrin" to a patient who is allergic to "Motrin". However, all experienced clinicians have experienced this. When given a large number of tasks to complete in a reasonable period of time, even though the study exercise had no time limit, humans will make such errors.

Table 5 describes the steps required in the process of ordering and administering a medication and the potential for error in each of these steps [4]. Note that since pediatric patients use smaller doses (less than a full vial or pill), additional calculations must be performed for pediatric doses resulting in a greater potential for error. Roughly 14 steps that have the potential for error are described here. Errors have been demonstrated to occur at each of these steps. Small error rates (e.g., 1\%) can add up to large numbers of errors. For example, if an inpatient unit carries out 100 medication administrations per shift and there are 14 steps per medication administration, this is a total of 1400 events. An error rate of $1 \%$ results in 14 errors per shift. An error rate of $0.1 \%$ still results in 1.4 errors per shift. At 3 shifts per day, this one unit has 4.2 errors every day. An error rate of $0.01 \%$ results in 0.42 errors per day, which is 12.6 errors per month. An error rate of $0.001 \%$ results in 15 errors per year on this one unit. A hospital with 20 nursing units will have 300 errors per year. An error rate of $0.0001 \%$ (1 in 1,000,000) will still result in 30 errors per year.

This study has focused on one type of error (i.e., recognizing that a drug is contraindicated with certain allergies or medical conditions) that is a basic medical and nursing function. Other studies have demonstrated that other types of errors occur as well. Bar coding technology is applicable to a specific type of error (correct patient, correct drug ordered for that patient), yet it does not address medication appropriateness and the accuracy of dose calculation, mixing, and administration and its effect on overall error reduction is modest [13]. Even within its limited scope, bar coding can be circumvented [14].

While it is well known that computer smart systems coupled with medical and nursing practice standards (five rights and nine rights of medication administration) result in inevitable errors, we continue to accept this as a standard. Alignment with existing care models suggest that if we practice better, be more careful, have a safety culture, and perhaps attempt to modify human behavior further, we can reduce error rates to something that we are comfortable with. Yet medical error studies consistently demonstrate an error concern. Can adding more machines, more rights of medication administration, more professionals, and more human behavior studies, reduce errors to a near zero point? A near zero error system should not be reliant on human processing and interpretation. Since we accept that humans make errors, human intervention steps must be checked by the system to confirm that the human intervention has been performed correctly. If we are to approach a near zero error point, the system must be changed dramatically such that existing care models are re-engineered to a new paradigm.

A potentially near zero error system is described below and in greater detail in Table 5 [4]. The advance is a re-engineering of the process placing more reliance on technology and machinery to manage tasks that would normally be done by humans, further reducing the potential for human error.

Patient identification is linked to a biometric marker or scanner code applied reliably to the patient. The patient is weighed simultaneously with a patient ID scan that records the weight via a direct link to the EMR without human keystroking or intervention. The patient's medication list and allergies are in the EMR and understood by the EMR in a smart fashion (i.e., not just a listing). Artificial intelligence (AI) prompts questions to facilitate the diagnostic process, which leads to a limited set of diagnostic and therapeutic options. AI prevents allergic medications and contraindicated medications by removing them from the limited set of therapeutic options. AI presents dosing range options and the clinician chooses from these options. The EMR then calculates the actual dose, sends an order message to the nurse, and a dispensing message to an automated dispensing unit that opens the drawer for the correct medication. The nurse removes the medication vial and scans its bar code on the dispensing unit to confirm that the correct medication has been removed. The vial is mixed with a self contained diluent (to prevent dilution volume errors). The vial is inserted into an automated injection device (AID) that has been assigned by the EMR. The AID scans the vial bar code to confirm that it is the correct medication. The EMR calculates the volume of administration based on dose and medication concentration. The AID with vial is brought to the patient's bedside by the nurse. The AID scans the patients ID barcode to confirm the correct patient. The AID is inserted into the IV line via a smart cassette. The AID manometer confirms a low pressure in the IV line and it begins the medication infusion at the rate that has been preprogrammed by the pharmacy for this particular medication. The AID sends a message to 
Table 5. Steps required in the process of ordering and administering a medication and the potential for error description and the error elimination method in each of these steps. (P) indicates an additional step that is necessary for pediatric patients only. [ ${ }^{\mathrm{A}} \mathrm{A}$ self-mixing vial is one that does not require the nurse to draw up a diluent volume since this step is potentially error prone. The vial contains two chambers with powder and pre-measured diluent in separate chambers. An inert rubber-like stopper separates the two. By pushing a protrusion on the self-mixing vial, the stopper is pushed away permitting the diluent and powder to mix in the correct concentration. Some medication vials are currently available as self-mixing vials (e.g., Solumedrol)].

\begin{tabular}{|c|c|c|}
\hline Step & Potential error & Error elimination method \\
\hline Patient identification & $\begin{array}{l}\text { Registration of name linking to the correct } \\
\text { medical record number. Duplicate names. Some } \\
\text { patients have more than one medical record } \\
\text { number, or name, or their name has changed. }\end{array}$ & $\begin{array}{l}\text { Patient is identified (ID). Biometric marker is recorded in EMR. } \\
\text { ID scanner code is applied onto patient }\end{array}$ \\
\hline Weigh patient (P) & $\begin{array}{l}\text { Patient is weighed in pounds instead of } \mathrm{kg} \text {. } \\
\text { Weight is obtained incorrectly. Visual weight } \\
\text { estimate is incorrect. }\end{array}$ & $\begin{array}{l}\text { Patient steps on or is placed on scale. Scale reads ID scanner } \\
\text { code. Alternatively a laser digitizer sizes the patient. Scale or } \\
\text { digitizer assigns weight to patient's ID. }\end{array}$ \\
\hline Weight is recorded $(\mathrm{P})$ & Weight is entered incorrectly in record. & $\begin{array}{l}\text { Weight/size information is recorded by EMR (direct link of scale } \\
\text { to EMR). }\end{array}$ \\
\hline $\begin{array}{l}\text { Medication history } \\
\text { obtained }\end{array}$ & $\begin{array}{l}\text { Medication history is not up to date. Patient fails } \\
\text { to recall medication list properly. }\end{array}$ & $\begin{array}{l}\text { Linked EMRs contain current medication list. Primary care, } \\
\text { specialty care, hospital, and all pharmacies are linked to the same } \\
\text { EMR. }\end{array}$ \\
\hline $\begin{array}{l}\text { Allergy history } \\
\text { obtained }\end{array}$ & Allergy history obtained incorrectly. & Linked EMRs contain current allergy list. \\
\hline $\begin{array}{l}\text { Clinical assessment, } \\
\text { diagnosis }\end{array}$ & Incorrect diagnosis. & $\begin{array}{l}\text { Artificial intelligence (AI) prompts questions. AI prompts for } \\
\text { physical findings. AI lists potential diagnoses with probabilities. } \\
\text { AI lists medication options. Clinician selects medication option. }\end{array}$ \\
\hline Medication order & $\begin{array}{l}\text { Incorrect medication selected. Medication } \\
\text { interaction not identified. Allergic medication is } \\
\text { ordered. Contraindicated medication is ordered. }\end{array}$ & $\begin{array}{l}\text { Clinician can only select from limited option set. AI prevents } \\
\text { allergic medications. AI prevents contraindicated medications. }\end{array}$ \\
\hline $\begin{array}{l}\text { Medication dose } \\
\text { calculation }(\mathrm{P})\end{array}$ & Calculation error. & $\begin{array}{l}\text { AI facilitates dosing range selection. Clinician selects dosing } \\
\text { range. Calculation is performed by EMR system. }\end{array}$ \\
\hline Nurse reviews order & Order reviewed incorrectly. & No interpretation or action required. \\
\hline $\begin{array}{l}\text { Medication } \\
\text { prepared/obtained }\end{array}$ & $\begin{array}{l}\text { Medication diluted incorrectly. Wrong } \\
\text { medication obtained. Look alike medication } \\
\text { obtained instead. Sound alike medication } \\
\text { obtained instead. }\end{array}$ & $\begin{array}{l}\text { EMR sends message to automated dispensing unit. Dispensing } \\
\text { unit opens medication drawer. Dispensing unit scans the vial bar } \\
\text { code. Dispensing unit confirms the correct vial. Vial is premixed } \\
\text { or must self-mix }{ }^{\mathrm{A}} \text {. Automated injection device (AID) is } \\
\text { dispensed }^{\mathrm{B}} \text {. AID }{ }^{\mathrm{B}} \text { is assigned the medication order by the EMR. }\end{array}$ \\
\hline $\begin{array}{l}\text { Calculate administration } \\
\text { volume }(\mathrm{P})\end{array}$ & $\begin{array}{l}\text { Calculation error. Concentration on label } \\
\text { interpreted incorrectly. }\end{array}$ & EMR calculates administration volume. \\
\hline $\begin{array}{l}\text { Draw up correct volume } \\
\qquad(\mathrm{P})\end{array}$ & Incorrect volume drawn. & $\begin{array}{l}\text { Vial is inserted into the } \text { AID }^{\mathrm{B}} \text {. AID wirelessly connects to EMR. } \\
\text { AID displays drug name, dose, time, and patient. AID scans vial } \\
\text { bar code. AID confirms that the vial is correct. AID draws up } \\
\text { correct volume. }\end{array}$ \\
\hline Administer medication & $\begin{array}{l}\text { Incorrect patient. Incorrect time. } \\
\text { Incorrect route. }\end{array}$ & $\begin{array}{l}\text { AID is brought to bedside. AID scans patient's ID scanner code. } \\
\text { AID confirms that this is the correct patient. AID is inserted in IV } \\
\text { line via smart cassette. AID manometer confirms low pressure } \\
\text { line. AID administers medication. AID alarms when } \\
\text { administration is complete. AID sends signal to EMR. EMR } \\
\text { medication administration record is updated. EMR alerts nurse } \\
\text { that administration is complete. }\end{array}$ \\
\hline
\end{tabular}


the EMR to enter the time of medication administration completion in the medication administration record (MAR) and it alarms to notify staff that the medication infusion is completed.

A future era that is nearly error free will be highly dependent on much improved machinery and much improved computer systems. Current EMR systems still require downtime maintenance that can render the system non-operational for prolonged periods of time. If we are going to create a system that is dependent on technology, it must be continuously reliable.

In conclusion, this study demonstrates that if an error escapes a smart system, nurses were able to identify most of these errors, but not all of these. The current system features high stress, self-esteem issues, time pressure, high volume, and high risk. The system must change radically to meet the public's expectations of being nearly error free which can only be achieved with smarter systems that are more resistant to human errors in addition to a culture of patient safety.

\section{REFERENCES}

[1] Conroy, S., Sweis, D., Planner, C., Yeung, V., Collier, J., Haines, L. and Wong, I.C. (2007) Interventions to reduce dosing errors in children: A systematic review of the literature. Drug Safety, 30, 1111-1125. doi:10.2165/00002018-200730120-00004

[2] Kaushal, R., Barker, K.N. and Bates, D.W. (2001) How can information technology improve patient safety and reduce medication errors in children's health care? Archives of Pediatrics \& Adolescent Medicine, 155, 10021007.

[3] Pedersen, C.A., Schneider, P.J. and Scheckelhoff, D.J. (2009) ASHP national survey of pharmacy practice in hospital settings: Dispensing and administration-2008. American Journal of Health-System Pharmacy, 66, 926946. doi:10.2146/ajhp080715

[4] Yamamoto, L. and Kanemori, J. (2010) Comparing errors in ED computer-assisted vs conventional pediatric drug dosing and administration. American Journal of Emergency Medicine, 28, 588-592. doi:10.1016/j.ajem.2009.02.009

[5] Rothschild, J.M., Keohane, C.A., Cook, E.F., Orav, E.J.,
Burdick, E., Thompson, S., Hayes, J. and Bates, D.W. (2005) A controlled trial of smart infusion pumps to improve medication safety in critically ill patients. Critical Care Medicine, 33, 533-540. doi:10.1097/01.CCM.0000155912.73313.CD

[6] Macdonald, M. (2010) Patient safety: Examining the adequacy of the 5 rights of medication administration. Clinical Nurse Specialist, 24, 196-201. doi:10.1097/NUR.0b013e3181e3605f

[7] Jones, J.H. and Treiber, L. (2010) When the 5 rights go wrong: Medication errors from the nursing perspective. Journal of Nursing Care Quality, 25, 240-724. doi:10.1097/NCQ.0b013e3181d5b948

[8] Elliott, M. and Liu, Y. (2010) The nine rights of medication administration: An overview. British Journal of Nursing, 19, 300-305.

[9] Committee on Pediatric Emergency Medicine (2007) Patient safety in the pediatric emergency care setting. Pediatrics, 120, 1367-1375.

[10] Senger, C., Kaltschmidt, J., Schmitt, S.P., Pruszydlo, M.G. and Haefeli, W.E. (2010) Misspellings in drug information system queries: Characteristics of drug name spelling errors and strategies for their prevention. International Journal of Medical Informatics, 79, 832-839. doi:10.1016/j.ijmedinf.2010.09.005

[11] Institute for Safe Medication Practices (2011) ISMP's list of confused drug names. http://www.ismp.org/tools/confuseddrugnames.pdf

[12] Hicks, R.W., Becker, S.C. and Cousins, D.D. (2008). MEDMARX data report. A report on the relationship of drug names and medication errors in response to the Institute of Medicine's call for action. Center for the Advancement of Patient Safety, US Pharmacopeia, Rockville.

http://www.labatecpharma.com/wp-content/uploads/2012 /02/2008MEDMARX-DataReport.pdf

[13] Young, J., Slebodnik, M. and Sands, L. (2010) Bar code technology and medication administration error. Journal of Patient Safety, 6, 115-120. doi:10.1097/PTS.0b013e3181de35f7

[14] Koppel, R., Wetterneck, T., Telles, J.L. and Karsh, B.T. (2008) Worka-rounds to barcode medication administration systems: Their occurrences, causes, and threats to patient safety. Journal of the American Medical Informatics Association, 15, 408-423.

doi:10.1197/jamia.M2616 